J Gen Pract 2016; 67(654): 31. DOI: https://doi. org/10.3399/bjgp17X688693.

2. Royal College of Physicians. National Early Warning Score (NEWS): standardising the assessment of acute illness severity in the NHS. Report of a working party. London: RCP, 2012

DOI: https://doi.org/10.3399/bjgp17X688969

\section{Colchicine in overdose}

We read with interest the letter from Lloyd warning of the danger of colchicine overdose $^{1}$ and agree that this can have devastating consequences. However, the majority of overdoses involve analgesics, antidepressants, hypnotics, anxiolytics, and antipsychotic medications whereas colchicine overdose appears to be an uncommon occurrence. ${ }^{2-4}$ Colchicine is an effective and useful treatment for both acute attacks of gout and prophylaxis against acute attacks when commencing uratelowering therapies such as allopurinol, particularly in the many patients who are intolerant of or have contraindications to non-steroidal anti-inflammatory drugs. 5,6 Although we concur with Lloyd that assessment of mood and risk of overdose should be considered when prescribing any medication, we urge prescribers not to abandon an effective treatment for this excruciatingly painful and frequently poorly managed condition.

\section{Edward Roddy,}

Clinical Senior Lecturer in Rheumatology and Consultant Rheumatologist, Research Institute of Primary Care and Health

Sciences, Keele University.

E-mail: e.roddylakeele.ac.uk

\section{Christian D Mallen,}

NIHR Research Professor in General Practice, Research Institute of Primary Care and Health Sciences, Keele University.

\section{REFERENCES}

1. Lloyd G. Colchicine in overdose. Br J Gen Pract 2016; 66(653): 605. DOI: https://doi.org/10.3399/ bjgp16X688333.

2. Prescott $K$, Stratton R, Freyer A, et al. Detailed analyses of self-poisoning episodes presenting to a large regional teaching hospital in the UK. Br J Clin Pharmacol 2009; 68(2): 260-268.

3. Doak MW, Nixon AC, Lupton DJ, Waring WS. Self-poisoning in older adults: patterns of drug ingestion and clinical outcomes. Age Ageing 2009;
38(4): 407-411.

4. Armstrong TM, Davies MS, Kitching G, Waring WS Comparative drug dose and drug combinations in patients that present to hospital due to selfpoisoning. Basic Clin Pharmacol Toxicol 2012: 111(5): 356-360

5. Jordan KM, Cameron JS, Snaith M, et al. British Society for Rheumatology and British Health Professionals in Rheumatology guideline for the management of gout. Rheumatology (Oxford) 2007 46(8): 1372-1374.

6. Richette P. Doherty M. Pascual E, et al. 2016 updated EULAR evidence-based recommendations for the management of gout. Ann Rheum Dis 2017; 76(1): 29-42. DOI: 10.1136/ annrheumdis-2016-209707. Epub 2016 Jul 25.

DOI: https://doi.org/10.3399/bjgp17X688993

\section{Barriers to lifestyle changes in people with diabetes}

The study on the impediments to good diabetes control by Elliott et al ${ }^{1}$ corresponds with our findings from an interview study of patients with diabetes from a deprived background in the northeast of England. We undertook semi-structured interviews with eight patients with established type 2 diabetes from one general practice and explored their perceived barriers to making lifestyle changes. The incidence of diabetes in the northeast of England is relatively high and is known to be inversely related to a low socioeconomic status, ${ }^{2-4}$ but there is little research exploring the reasons for the link with deprivation. Our results highlighted four common themes: dietary education, motivation to change, family support, and comorbidities.

Patient education was the most commonly reported barrier, related to poor dietary education and misperceptions gained during childhood on healthy foods. Participants struggled to find the motivation to change their lifestyles. This fluctuated in some participants, who reported returning to bad habits during prolonged periods of no medical contact. Interestingly, the level of perceived support a patient felt they had seemed to correlate with their overall motivation. Participants who were in a relationship commented on how their partner acted as a source of continual encouragement to help them continue with the lifestyle regimen they had been given. However, following a healthy lifestyle was challenging for family members of our patients, especially those who were part of a big family with children. Surprisingly, financial barriers were felt to be less of an issue than might have been expected: most participants suggested that the cost of leading a healthier lifestyle was balanced by the cost of unhealthy habits such as 'takeaways'. Finally, the participants' overall health and the consequential impact of their comorbidities were highlighted as an important barrier to following a healthy lifestyle.

Harley Fuller,

Medical Student, Newcastle University.

Hugh Alberti,

GP, Subdean for Primary and Community Care, Newcastle University.

\section{REFERENCES}

1. Elliott AJ, Harris F, Laird SG. Patients' beliefs on the impediments to good diabetes control: a mixed methods study of patients in general practice. $\mathrm{Br} J$ Gen Pract 2016; 66(653): e913-e919. DOI: https:// doi.org/10.3399/bjgp16X687589

2. Connolly V, Unwin N, Sherriff $P$, et al. Diabetes prevalence and socioeconomic status: a population based study showing increased prevalence of type 2 diabetes mellitus in deprived areas. J Epidemiol Community Health 2000; 54(3): 173-177.

3. Robbins JM, Vaccarino V, Zhang H, Kasl SV. Socioeconomic status and diagnosed diabetes incidence. Diabetes Res Clin Pract 2005; 68(3) 230-236.

4. Ricci-Cabello I, Ruiz-Pérez I, Olry de Labry-Lima A, Márquez-Calderón S. Do social inequalities exis in terms of the prevention, diagnosis, treatment, control and monitoring of diabetes? A systematic review. Health Soc Care Community 2010; 18(6): 572-587.

DOI: https://doi.org/10.3399/bjgp17X689005

\section{The recipe for general practice}

The production process for fresh GPs from our specialty training is like the process for making sausages: a pleasing end product, but we distract ourselves from thinking about the content too much. ${ }^{1,2}$

The difficulties of the right mix of hospital training placements is that, for general practice, every hospital-based speciality is both relevant, and yet irrelevant. But why hospital-based training at all? No GP programme director has yet been troubled 
by the paediatricians demanding that their trainees receive placements in primary care - where the majority of paediatric practice occurs in the UK - and the ambition to integrate 4 months of general practice into every foundation placement remains unrealised. Why do we, as a college, and as a specialty, seem satisfied with filling our training programmes with the leftovers and castoffs from other specialties' training? Why be satisfied with what we are given?

The very best place for general practice specialty training is within general practice, and for too long we have pretended that hospital-based placements are essential to develop good GPs, when the reality is that our trainees are required to keep the hospital service going. We need an end to the calls that paediatrics, psychiatry, and the rest are essential, and it is time to shout that GPs should be wholly trained within general practice for at least 3 years. Shout loudly for the proper resourcing of our skilled trainers to deliver the generalist, broad-based training that hospital practice will never give us.

Steven Taylor,

GP Partner, Coastal Partnership, Norfolk.

E-mail: dr.steven.taylorlamac.com

\section{Competing interests}

Steven Taylor is Programme Director for Norfolk GPSTP, although he does not write in this capacity.

\section{REFERENCES}

1. Hawthorne K. Child health training and the College. Br J Gen Pract 2016; 66(653): 605. DOI: https://doi.org/10.3399/bjgp16X688105.

2. Sharvill NJ. Child health training: why does the College not act? Br J Gen Pract 2016; 66(648): 350. DOI: https://doi.org/10.3399/bjgp16X685801

\section{Our ailing profession}

After 25 years of working with clinicians and managers of many kinds, including leading the RCGP leadership programme for 5 years, I have come to the view that, all too often, GPs disempower themselves by responding to even the most valuable and practical of thoughts, ideas, and opportunities with one or more of the following three responses: first, the problem with that is; second, we're doing that already; and third (we shouldn't have to because) it's their fault.

Much of the value in many leadership programmes is in helping people develop alternative responses.

David Zigmond demonstrates all three in his description of how he undermined his colleagues as they tried to develop constructive ways of improving the working lives and experiences of those in primary care, and encouraging younger practitioners to remain and to flourish in their chosen career.

What a pity that he chose to send you his description, and that you chose to publish it. As a sympathetic observer I strongly suggest that challenging this attitude of impotent victimhood would do more to alleviate the recruitment problems in primary care than anything else.

Valerie Iles,

Director Really Learning, Honorary Fellow RCGP.

E-mail: v.ilesdareallylearning.com

\section{REFERENCE}

1. Zigmond D. Our ailing profession: we need more than resilience and replenishment $\mathrm{Br} J$ Gen Pract 2016; 66(653): 622-623. DOI: https://doi. org/10.3399/bjgp16X688213.

DOI: https://doi.org/10.3399/bjgp17X689029

\section{Our ailing profession: author's response}

Valerie Iles's response to my article 'Our ailing profession: we need more than resilience and replenishment ${ }^{\prime 1}$ shows that my major points are unclear, to at least one reader.

I certainly do not wish to attribute blame or victimhood, or encourage aggrieved despondency. My article, though, takes a very wide and long view and concludes that our professional healthcare problems now have the kind of nature and roots as to be cultural. Culture means that no one is to blame, yet we are all responsible.

Neither do I wish to carelessly stymie colleagues' 'ways of improving [their] working lives' and relationships. However, it is important to be vigilant to the bigger picture. My article described a conference where dispirited and enervated young doctors were offered palliative suggestions of mindfulness, stress management, and enhanced breathing techniques. Yes, I accept that such devices may help us 'get by', but in no way address cardinally important bigger questions: how do we understand our rapidly increasing stress, distress, demoralisation, and burnout? If we can understand, what can we do about it?

The danger of merely propagating coping strategies is that they can serve to parry and obscure such questions about pathogenesis.

In the last two decades I have seen how the $4 \mathrm{Cs}$ - competition, commodification, commissioning, and computerisation have incrementally depersonalised and demoralised our NHS. The Health and Social Care Act 2012 has exacerbated this. Dismissing such complex analysis as meretricious 'blame' will help none of our longer-term interests. Nor will Valerie Iles's recommendation that my writing should not be published. What kind of culture does that lead to?

Yes, I have many positive suggestions. Some are summarised in 'Plummeting morale of junior doctors: one branch of our blighted tree of welfare', accessible via my home page. ${ }^{2}$

\section{David Zigmond,}

GP, St James Church Surgery, London. E-mail: infolajackireason.co.uk

\section{REFERENCES}

1. Zigmond D. Our ailing profession: we need more than resilience and replenishment $\mathrm{Br} J \mathrm{Gen}$ Pract 2016; 66(653): 622-623. DOI: https://doi. org/10.3399/bjgp16X688213.

2. Zigmond D. Plummeting morale of junior doctors: one branch of our blighted tree of welfare. Letter to the Chair of the Academy of Medical Royal Colleges. 2016. http://www.marcolearningsystems.com/pages/david-zigmond/ new- $1 /$ n31.03.16\%20sue $\% 20$ bailey $\% 20+\% 20$ cover\%20page.pdf laccessed 12 Jan 2017).

DOI: https://doi.org/10.3399/bjgp17X689041 